\title{
The Challenge of Global Environmental Change in the Anthropocene: An Analysis of Brazil and China
}

\author{
Leila da Costa Ferreira' ${ }^{1}$ Fabiana Barbi ${ }^{1}$
}

Received: 13 April 2016/Accepted: 6 May 2016/Published online: 19 May 2016

(C) Fudan University and Springer Science+Business Media Singapore 2016

\begin{abstract}
Human activities are central to the debate on global environmental changes, constituted as unprecedented challenges to contemporary societies in transition to the Anthropocene. Regarding social and political dimensions of global environmental changes and the perspective of risk society, this article analyses how Brazil and China are politically responding to these challenges. It provides a summary of the main events and trends of environmental policies in Brazil and China, two countries that have been noted for their international importance and, above all, for the importance of environmental issues at the core of their actual political processes. From a theoretical point of view, an intercrossed analysis capable of fostering dialogue between environmental sociology, social theory and sustainability is proposed, considering international relations and the notion of governance. For both countries, the question that remains is whether the actions proposed and the existing political and institutional structures are sufficient to respond effectively to contemporary environmental risks, mainly in time to prevent irreversible climate change.
\end{abstract}

Keywords Risk · Global environmental change · Anthropocene · Brazil · China

\section{Introduction}

From the last two decades of the twentieth century, the environmental issue has become a global problem, not only mobilizing civil society and media sectors organizations, but governments of all regions of the planet. In this scenario, especially in recent decades, an interesting institutionalization process of the

Fabiana Barbi

fabarbi@gmail.com

1 University of Campinas, Campinas, Brazil 
environmental issue in the world is observed, which has increasingly called the attention of the scientific community.

Therefore, this article aims to provide a summary of the main events and trends of environmental policies in Brazil and China, two countries that have been noted for their international importance and, above all, for the importance of environmental issues at the core of their actual political processes.

From the development of sociological horizon investigations, the development of a "historical reconstruction" of environmental problems in these two societies is intended, with emphasis on political and institutional changes occurred in the 1970-2010 period. Therefore, efforts are concentrated mainly in the analysis of institutional progress of environmental policies in China and Brazil, highlighting the study of official documents and academic papers on the subject.

In this context, special emphasis is given to global environmental issues, particularly to the climate issue, which is presented as one of the main challenges of the global society of the twenty-first century and a central element of the discussion of the so-called Anthropocene (Biermann et al. 2012; Biermann 2014). From a theoretical point of view, an intercrossed analysis capable of fostering dialogue between environmental sociology, social theory and sustainability is proposed, considering international relations and the notion of governance.

\section{High Modernity and the Anthropocene: The Risk Society and the Global Environmental Change}

According to Beck (1992, 1995, 2010a), climate change can be considered a component of a new set of contemporary environmental risks produced by the scientific and technological development process, which is qualitatively different from the typical risks of pre-industrial and industrial societies. These new postindustrial risks would be characterized thus by their global scope, by the incomplete understanding of their causes and consequences, by being immeasurable and impossible to be compensated, most often invisible (i.e., phenomena that require expertise in relation to their recognition and their measurement). Therefore, they would be uncontrollable and difficult to have responsibilities assigned, often irreversible.

This set of elements constitutes the scenario of the issue addressed by this article, with special emphasis on the issues and challenges given by global warming. In this sense, it is questionable whether the formulated actions would be efficient, that is, capable of producing the desired climate balance or are mere palliatives that, ultimately, will promote the maintenance of the current model of action that will not result in the mitigation of global environmental problems. In other words, are we actually dealing with the problem as indeed it should be done, that is, a serious, urgent and detailed way, or are we just walking an irresponsible path to get around the issue, committing future generations by not making the necessary changes?

In a short period of time, the climate change issue has become one of the most important problems of the twenty-first century (Giddens 2009). Since 1988, the Intergovernmental Panel on Climate Change (IPCC), jointly established by the 
United Nations (UN) and the World Meteorological Organization (WMO), has been dedicated to understand the global climate system functioning and its governance and to propose concrete actions to face the possible future climate scenarios (Ferreira et al. 2016). The most significant scientific breakthroughs of developed activities were presented in recent IPCC reports, when the existence of a relative consensus on the cause of the global warming issue was reported, concluding with a significant level of confidence that the change is real and that the increase in the average temperature of the Earth's surface is a result of human activities combined with the natural variation in the global climate system (IPCC 2007, 2013).

This fact represents an important advance regarding the issue discussion, particularly by countering persistent arguments that supported, with some penetrating power in public opinion, that global warming would be due solely to natural causes, being a result of biogeological cycles of the planet. According to this position proponent, by being a phenomenon only produced by natural causes, there is nothing that could be done to confront it but to accept it and learn to live with a future characterized by conditions beyond human wills.

Although the scientific community recognizes that the planet's temperature is characterized by a complex phenomenon subject to cyclical variations in long term, the debate is that it is possible to evaluate the contribution of human activities to the so-called "enhanced greenhouse effect" and, likewise, to note that the pace of this phenomenon has been accelerated since the advent of the Industrial Revolution and its internalization in the Western lifestyle (Wilbanks and Kates 1999; Beck 2000a; Pittock 2005). Changes currently experienced apparently unprecedented challenge adaptability and planet response, since they would still be unknown (Young et al. 2006), despite several scientific initiatives aimed at providing a better understanding of these processes in an integrated global scale (Rockström 2009). In general, the complexity of our historical condition is so unique that environmental changes caused by human intervention are understood as the foundation of a new historical and geological age: the Anthropocene (Will et al. 2011).

Living in a global society means facing multiple risks molded by various "stressors", as there are large uncertainties in terms of what the world will be like in 20,30 or 40 years. In this universe, it is only possible to display odds and the projection of possible scenarios that materialize as social imaginary. Based on this, the high modern society is directly involved in the challenge of managing a growing structure of risks that have the Anthropocene as a demarcative element of a new era.

In terms of responses to climate change, it has been argued that governments are important protagonists that play a fundamental role in defining standards, institutions and appropriate ways of governance to address these risks at different levels and scales (Giddens 2005, 2009; Alber and Kern 2008; Bulkeley and Newell 2010; Ferreira et al. 2016). Therefore, the Anthropocene challenge imposes the need for a global dialogue, capable of balancing the different local interests for the sake of a common future.

Beck $(1992,1995,2009)$, in this context, suggests the need of the nature of the current ecological crisis to be reconsidered since the side effects of industrial production are characterized as a result of a deep institutional crisis of industrial society. This reasoning can be applied to the climate change scenario, in which 
causes were deeply rooted in modern societies: seemingly innocuous and invisible substances such as methane $\left(\mathrm{CH}_{4}\right)$ and carbon dioxide $\left(\mathrm{CO}_{2}\right)$ are released into the atmosphere as "development products" (agricultural industrialization, increased energy consumption and economic growth) by changing their composition, with incalculable consequences (Bulkeley 2001; Ferreira et al. 2016). Thus, as thought by Beck, the Anthropocene would have the risk as their main horizon. In this sense, living in this age would mean living with probabilistic estimates of future catastrophic scenarios that highlight the harmful effects of modern social order.

According to the debates around the risk theory presented by Beck $(1992,2009)$, the risks given by climate change are characterized by escaping from the sense perception, that is, they are phenomena located in the abstract of physical equations and chemical formulas, remaining thus invisible to the daily perceptions. They can be changed, expanded, dramatized or minimized within the knowledge and thus are open to definition and social construction. Moreover, these risks are closely related to the future and to the misfortunes evaluated in probabilistic projections regarding different future possibilities.

In the society of risk and in the Anthropocene era, the technical and industrial development causes unpredictable, invisible and incalculable risks that require selfreflection and self-confrontation of society with respect to the base of social cohesion and the examination of the grounds of their rationality. The boundaries between nature and culture are pulverized against a historical setting permeated by multiple porosities between natural and artificial, between nature and culture. The risk that characterizes contemporary industrial society is closely involved with future projections, with the misfortunes actively assessed in relation to the possibilities and the probable situations with which our society has only limited experience (Beck 1992, 2000b, 2009; Giddens 2005, 2009). These characteristics are closely related to the risks of climate change and are influenced by the increasing globalization (Young et al. 2006). The Anthropocene and the society of risk, therefore, have an interesting elective affinity that makes them to present multiple connections of meaning: the risk seems to be a key element for ways to acting, thinking and sense that shall guide the forms of social life created in the Anthropocene.

It is difficult to know the level of such risks and, in many cases it is impossible to predict their effects before it is too late, since we do not know what changes might happen next, or what are the dangers that can occur to these new modifications. Thus, the challenge is how to establish effective policies to address different problems, since the future is uncertain and assessing risks accurately until the conjectured risks materialize is not possible (Giddens 2009).

In this scenario, political action and intervention carried out at the local, national and international levels will have a decisive effect on the establishment of acceptable limits for the global warming issue, especially with regard to the scenario of adaptation to the effects and phenomena that are currently in progress (Giddens 2009). International agreements, for example, are essential attitudes, and actions of other spheres and actors such as NGOs and the private sector also happens to play a key role in addressing the problem. Even so, the State keeps providing a unique and structuring power force for social organization and, as such, should be convoked, 
especially if more serious impacts involving the global warming scenario indeed happen (Zehr 2014).

In terms of climate change policies, the debate in Brazil and China is still in early stages and there are, therefore, a number of issues still to be worked out in the coming years. If we consider that we are debating and deciding on the futurealthough the future has become the present - the quality of life in the Anthropocene era, not only for humans but also for many ecosystems, depends on actions and measures to be taken now (Ferreira et al. 2016).

In this context, this debate provides reasonable arguments for the defense of engagement in collective and political dialogues in the negotiation and design of proposals that can improve responsiveness to the challenges so that these responses are not only palliative towards the social and economic maintenance of the status quo, of political interests and unsustainable patterns of human development.

\section{Global Environmental Change in Brazil and China}

In this topic, some of the main events and trends of environmental policies in Brazil and China are explored. Both Brazil and China have many challenges to be faced in relation to the set of problems that make up the environmental issue in a world characterized by high modernity, society of risk and by the global environmental changes. This is not, however, a local issue only for these two countries; since this is a global issue, it should be part of the political agenda of other countries around the world, especially with regard to the dilemma of prioritizing environmental concerns at the expense of economic development on a planet that is facing significant environmental changes.

Given the range of possibilities that a study on the scenario of global environmental change in Brazil-China presents, the analytical approach used for the development of investigations was defined and specifically positioned to study the problem presented, that is, climate change.

\subsection{Brazilian Strategies with Respect to Climate Change}

Regarding environmental concerns in Brazil, it is always difficult for them to become a priority in Brazilian politics. The analysis of the political and administrative dimension of environmentalism in Brazil reveals a complex legal and institutional framework increasingly growing, defined in public administration levels since the 1970s. Indeed, several government environmental agencies have been created along with a considerable number of environmental regulations (Ferreira and Tavolaro 2008; Ferreira et al. 2016). Thus, there were several policies aimed at improving the quality of life of urban and natural areas in the last 30 years or more, whether at the federal, state and local levels.

The creation of the Brazilian Forum on Climate Change (FBMC, in Portuguese) was, in 2000, one of the first moves at the federal level related to climate change. They aimed at presenting, educating and mobilizing society for the discussion of issues related to global warming. In 2007, the federal government established the 
Interministerial Committee on Climate Change, and the main tasks were planning and implementing of a National Policy on Climate Change, through a National Climate Change plan (Barbi et al. 2015; Ferreira et al. 2016).

During the administration of President Lula (2003-2010), the National Policy on Climate Change (NPCC, in Portuguese) was approved, in 2009. Two weeks before the 15th Conference of the Parties to the Framework Convention on Climate Change of the United Nations in Copenhagen (COP 15), Brazil moved from its historical position in negotiations and adopted a voluntary target for reducing emissions of greenhouse gases (GHG) from 38 to $36.1 \%$, that is, $9 \%$ of the total projected emissions for 2020 (Brazil 2009; Viola and Franchini 2012; Viola et al. 2013; Ferreira et al. 2016).

The NPCC stipulated the preparation of Sectoral Plans, developed between 2012 and 2013. The national policy agenda is focused on the implementation of these sectoral plans. In general, the national planning emphasized the small contribution of Brazil in generating global problems related to the environment, if compared with the contribution of other emerging and developed economies, and indicated that the country had done its best in mitigation actions, but would be willing to adopt more comprehensive environmental policies to address the problems in question (Ferreira et al. 2016).

During the process of creating and promulgating the Forum and National Policy, other public events, research institutions and civil society organizations have been established at the federal and state levels. Among them are: the presentation of the Climate Network; the creation of the National Institute of Science and Technology for Climate Change; the development of a network of civil society organizations called "Climate Observatory"; the launch of the Research Program on Global Climate Change in the State of São Paulo by FAPESP (Foundation for Research of the State of São Paulo); and the creation of the Brazilian Panel on Climate Change (PBMC) (Ferreira et al. 2016).

PBMC, launched in 2009 by MCTI (Ministry of Science, Technology and Innovation) and the MMA (Ministry of the Environment), tried to strengthen relationships between climate science and policy. It was structured based on the IPCC, in order to provide scientific assessments on the impacts, vulnerability and adaptation actions and mitigation of climate change. The "First National Assessment Report" of PBMC was presented in 2012 during the Rio + 20 (PBMC 2013). The importance of this report lies in the elements it can provide for the implementation of climate policy in the country, both related to mitigation and adaptation.

Data presented by the Anthropic Brazilian Inventory (MCT 2010) show that in the last 15 years, Brazil has increased its GHG emissions at very significant levels. Between 1990 and 2005, $\mathrm{CO}_{2}$ emissions increased by about $65 \%$ on the sum of all surveyed sectors; only coal mining-related emissions decreased by $29 \%$. The Change of Use of Land and Forest was responsible for most of the $\mathrm{CO}_{2}$ emissions in 2005, representing $77 \%$ of total emissions. During the analyzed period (1990-2005), emissions from this sector grew $64.3 \%$ (Ferreira et al. 2016).

According to Viola (2015), the situation is very different between 2009 and 2015. In 2009, the country was coming from a dynamic of economic prosperity and 
starting to think long term. According to the same author, in a society made by the short term, climate policy is unachievable. The author points out that we had a macroeconomics seemingly in order; in addition, the whole "control" process of the Amazon issue, in fact, was a consequence of the inability to control deforestation. Thus, we went through 2004 when all was uncontrollable, for years of systematic and aggressive reduction of emissions. We were at the end of a virtuous cycle of "empowerment" of forces favorable to the mitigation of climate change and "decarbonisation" within the ministerial cabinet.

In fact, now, according to Viola (2015), we are in an opposite period. First, the country is taken by the short term. There is a deep economic, political and moral crisis. This causes a social and collective action capacity breakdown. This means that the Brazilian "decarbonisation" forces, which go far beyond the environmentalists, are in a very unfavorable social context.

In relation to adaptation to the effects of changes in the climate system, Brazil has implemented a subsistence agriculture program in the Northeast region of the country aimed at the improvement of plants that would be adapted to climate change and has been dedicated to keep its main ecosystems such as Amazon and Atlantic Forest, through the establishment of biological corridors. However, the country needs to implement permanent adaptation actions to resolve, once and for all, problems related to climate change affecting the population.

According to Nobre (2010), the first step to the adaptation would be reducing vulnerability to exposure to climate at present and this is slowly happening in Brazil. The population in the Northeast is often affected by drought, which has always occurred in the region. Some measures to adaptation to drought, which have been implemented in the Northeast, are the construction of cisterns to collect rain water, as exemplified by the author. However, when the drought occurs for long time as has happened in the region in recent years, accumulating water is not possible because there is almost no rainy season. Therefore, adaptation to climate change has to be a permanent measure. It cannot be solved now, on a particular climate problem that affects a population, and then, next year, an assessment is done to decide what to do if the problem re-emerges.

\subsection{The Chinese Perspective on the Global Environmental Changes}

As a global actor, China can be considered a key country in the international climate policy (Basso and Viola 2014; Ferreira and Barbi 2014; Moreira 2015). Moreover, it is also the largest GHG emitter in the world since 2007, when it overtook the USA (Moreira 2015).

One of the reasons that makes China a key actor in climate negotiations, according to the same author, is its status and influence in the G77, a group that brings developing countries to increase their bargaining power in the UN system. China's performance in the G77 generates prominence in climate negotiations, since the drafting of the document that became the Climate Convention in 1992, going through the negotiations for the establishment of the Kyoto Protocol, and conquering more and more importance in the rounds of the international environmental order of climate change. 
China can be considered the engine of economic growth in the world due to its rapid development and its economic and industrial expansion. This scenario is accompanied by a strong growth of population density of its urban areas, a fact directly connected to the emergence of mega cities since the 1990s. As a result, energy consumption has grown significantly as well as emissions of pollutants discharged into the air, which has been producing negative effects on the population health. Consequently, pollution of air and water is one of the most serious environmental problems presented by China, but other environmental issues including the reduction of water resources, the accelerated deforestation and a number of threats to human health, arising from climate change, should also be highlighted. Thus, the size of the country, the magnitude of its population and the current scenario of strong and rapid development cause environmental problems from spreading not only locally, but to the rest of the world, not only through macroeconomic policy impacts, which generate disorders to the financial equilibrium of different countries, but also with regard to cross-border pollution, in the form of acid rain and dust storms, and the strong contribution of the country to the global climate change scenario (MacBean 2007; Chan and Yao 2008; Huang et al. 2010; Oliveira 2011; Xie 2011; Ferreira et al. 2016).

According to Moreira (2015), China is rich in fossil energy resources, especially coal reserves, but he considers that, in terms of per capita possession of these resources, it is below the world average. The country is at the forefront in reserves of coal, iron, copper, bauxite, lead and zinc. China's forest cover was, in 2008, 195.45 million hectares, and is one of the "megadiverse" countries. According to the same author, in 2005 China produced about $7467 \mathrm{Gt} \mathrm{CO}_{2} \mathrm{eq}, 80 \%$ of which were $\mathrm{CO}_{2}$ emissions. Of these, emissions from the energy sector account for $90.4 \%$ of the total, while emissions from industrial processes account for $9.5 \%$ of the total, which are the sectors that emitted more $\mathrm{CO}_{2}$ in China. The country credits the rapid increase in GHG emissions between 1994 and 2005 to the economic development and improvement of the standard of the population living. In this period, total emissions of $\mathrm{CO}_{2}, \mathrm{CH}_{4}$ and $\mathrm{N}_{2} \mathrm{O}$ increased from $3.65 \mathrm{Gt} \mathrm{CO}_{2}$ eq to $6.6881 \mathrm{CO}_{2}$ eq.

Despite this growth, China emphasizes that its per capita emissions in 2005 arising from fossil fuels were 3.88 tonnes, that is, the equivalent of $34 \%$ of the average of the Annex I countries of the Framework Convention on climate change, which represent $20 \%$ of the world population and that produced $57 \%$ of global GDP, based on purchasing power parity, and account for $46 \%$ of global GHG emissions (IPCC 2007). It is important to note that these per capita data strongly support the arguments of large countries such as China, a large emitter in absolute terms, but with a huge population, which makes its per capita emissions to diminish dramatically and justify, in its view, the position of not accepting commitments regarding GHG emission reduction before the convention.

In a continuity scenario of economic development and increase in energy consumption, $\mathrm{C}_{2}$ emissions per capita will continue to grow in leaps and bounds until the per capita GDP reach 10-15 thousand dollars a year, which should happen after 2015. Furthermore, it is expected that China's population continues to grow steadily over the next decade, as well as urbanization rates, which grew on average $1.37 \%$ per year in the 2000-2010 period. According to the Chinese government, 
these increases will require construction of urban infrastructure on a large scale, more iron and steel, cement and other products that require high energy consumption, which will lead to increased energy use and $\mathrm{CO}_{2}$ emissions (Keith et al. 2014; Moreira 2015).

In this sense, the government policy adopted by China constantly faces the dilemma of prioritizing economic growth or prioritizing environmental protection, especially since the introduction of reforms made by Deng Xiaoping (four modernizations and the opening to the international market), in 1978. During most of its past, China considered nature as a restriction to be dominated or overcome, rather than as something to be harmonized and preserved (Ferreira et al. 2016).

Hung and Tsai (2012) highlight the challenges that China faces as a result of climate change and their costs. Challenges include glacier melting, especially in Tibet and Tiansham; loss of agricultural production, which can be reduced by up to $10 \%$ by 2030; increased number of droughts, storms, floods and natural disasters caused by extreme weather; rising sea level, which will affect 67 million people; dwindling resources, severe pollution problems and a rapidly growing economy. All are factors of a typical development dilemma, and the potential cost of climate change to the country is extremely high.

In this sense, China began to develop, since the 1970s, environmental legislation and to build institutions aimed at protecting the environment. The laws on environmental protection in China are considered the most progressive than any developing nation, at least on paper. It is noteworthy, for example, the presence of a Ministry dedicated exclusively to the promotion and compliance with environmental laws: the State Board of Environmental Protection. In addition to the political society, the active presence of non-governmental organizations (NGOs) concerned with environmental protection is verified. Lawsuits against polluters have been fought in the courts, some successfully. However, at the provincial level, in important sections of the political cities administration, it appears that the existence of conflicting objectives, as well as strong corruption in State management, ultimately weaken severely the effectiveness of policies and targeted legal measures for environmental protection on Chinese soil (MacBean 2007; Oliveira 2011; Ferreira and Barbi 2013; Ferreira et al. 2016).

As can be understood of the above observations, China faces a general process of change with respect to policies for the environmental issue. This set of changes, which runs through the central and local policy of China, as well as its civil society, reveals a significant increase in attention given by different sectors of the country to environmental issues. This is due to growing awareness of the local government regarding the problems of local order and its repercussions on the global level; these complementary dimensions share the same horizon, the urgent need for environmental degradation interruption due to its adverse effects. This reflection, in turn, has been driven by the civil society participation, which has pushed the government to promote local and national actions in the environment and society (Huang et al. 2010; Ferreira et al. 2016).

To cope with an increasing range of global environmental issues, the Chinese government has become more engaged internationally in the last two decades. In 1990, the State Council announced a statement on the "Problems and positions 
related to global environmental issues", in which principles have guided China's position on global climate negotiations. They emphasized the responsibility of developed countries for environmental crisis, the harmony between environmental protection and economic development; the recognition of development right of countries; the sovereign equality of all countries and the need to create funds for developed countries (Oliveira 2011; Ferreira et al. 2016).

With regard to climate change, China has engaged in the international debate, developing domestic institutions appropriate to the issue and collaborating with the Climate Convention in those international negotiations that led to the Kyoto Protocol. In addition, as a council member of the United Nations Environment Programme Council (UNEP), China adopted and signed 50 international treaties, 15 are conventions and 27 bilateral agreements related to environmental protection during the 1990s. However, since international negotiations were set to be consolidated and had to be absorbed internally, the intentions of the Chinese representatives clashed with international aspirations. In this context, the domestic position that global policies could not reduce the growth rate in the country was expressed (Oliveira 2011; Ferreira et al. 2016).

Although the opening to the international debate is a reality, as can be seen with the largest participation of the Chinese government in international forums, GHG emissions in China continue to grow. ${ }^{1}$ In this sense, due to pressure from the international community, the country began to play a more proactive role with respect to the commitments made in the negotiations on climate change. In 2007, for example, China announced the National Climate Change Program and created the National Leadership Group on Climate Change. In 2009, China committed to the international community with the decision to significantly cut GHG emissions by 2020 , by increasing the use of "clean" fuel sources by $15 \%$, as well as by increasing the pace of reforestation and developing a "green economy". However, according to the Chinese leadership, this structure of commitments will hardly be achieved since there is the dilemma of reducing emissions and decreasing economic growth, which would produce effects on the current pace of social development currently observed in China (Huang et al. 2010; Oliveira 2011; Ferreira et al. 2016).

So, in this brief overview of environmental problems in China, the country has adopted a series of policies and programs aimed at mitigating climate change, either within the civil society and the government sphere. The measures stood out for its diversity and coverage. Oliveira (2011), for example, notes that the China National Institute of Standardization adopted new rules for the regulation of electrical appliances efficiency to reduce by $10 \%$ energy consumption by 2010. In cities as Beijing, Chungquing, Shanghai and Tianjin, similar measures have recently been introduced to reduce by $65 \%$ the energy consumption of public buildings. In the transport sector, China already has one of the largest fleets in the world of bus powered by compressed natural gas. The country also invests in the development of electric cars, in the set of projects called Clean Development Mechanism (CDM),

\footnotetext{
${ }^{1}$ From 1994 to 2004, the average annual growth rate for emissions of greenhouse gases was about $4 \%$. Since 2006, China overtook the USA and became the largest emitter of greenhouse gases in the world (Huang et al. 2010).
} 
which tries to create leading groups in the sector and the establishment of research institutions on the subject.

Other environmental issues in China that drew attention were the biodiversity protection, desertification control, nuclear safety, the protection of the ozone layer and marine pollution (Huang et al. 2010; Ferreira et al. 2016). Therefore, the increasing participation of the country in the global public sphere should be noted, especially regarding the treatment of subjects that make up the contemporary environmental agenda such as energy issues (problems related to nuclear energy and the search for alternatives to fossil fuels) and issues that impact on the climate change issue, as in the case of GHG emissions.

\section{Concluding Remarks}

Human activities are at the center of debate on global environmental change, configured as unprecedented challenges to contemporary societies, transitioning to the Anthropocene. Within the understanding of the social and political dimensions of global environmental change from the risk society perspective, this article highlighted how Brazil and China are responding to these challenges.

It was presented that governments are relevant actors in proposing appropriate forms of governance of climate change, understanding that they are not the only ones facing this challenge. It is important to emphasize that the importance of this actor does not mean defending a government in its entire instance.

Regarding Brazil, the analysis of the political and administrative dimension of the climate issue reveals a legal and complex institutional structure increasingly growing. In fact, some divisions of government were created with a specific policy to address the issue. However, this does not guarantee efficient and necessary responses that address the magnitude of the issue, as stated by scientists. Moreover, the question is whether Brazil will fulfill the objectives defined by the national reduction policy of GHG emissions, in a context of increasing levels of deforestation and energy options of GHG emitters.

Regarding China, the challenges are even greater, as the country remains focused on economic growth, and coal continues to dominate the energy matrix. The country's choices will continue to strongly influence global efforts in relation to climate change.

In both cases, the question remains, that is, whether the actions proposed and the existing political and institutional structures are sufficient to respond effectively to contemporary environmental risks, mainly in time to prevent irreversible climate change.

The real focus of this debate is the transformation of basic concepts and institutions established during the development of contemporary society (Beck $2010 \mathrm{a}, \mathrm{b})$, that is, the transformation of human activities responsible for global environmental change. 


\section{References}

Alber, G. and K. Kern. 2008. Governing climate change in Cities: modes of urban climate governance in multi-level systems. In: OECD International Conference, Competitive Cities and Climate Change, 2nd Annual Meeting of the OECD Roundtable Strategy for Urban Development. Milan, Italy.

Barbi, F., G.B. Mozzer, R.D. Martins, and L.C. Ferreira. 2015. Mudanças climáticas na Rio + 20: uma reflexão sobre os 20 anos de negociações climáticas no Brasil. In Governança Ambiental no Brasil: Entre o Socioambientalismo e a Economia Verde, ed. F. Castro, and C. Futemma. Jundiaí: Pacco Editorial.

Basso, L. and E. Viola. 2014. O Progresso da política energética chinesa e os desafios na transição para o desenvolvimento de baixo carbono, 2006-2013. Revista Brasileira de Política Internacional. 57. (Brasília).

Beck, U. 1992. Risk society. Beverly Hills: Sage.

Beck, U. 1995. Ecological politics in an age of risk. Cambridge: Cambridge University Press.

Beck, U. 2000a. What is globalization?. Cambridge: Polity Press.

Beck, U. 2000b. Risk society revisited: theory, politics and research programmes. In The risk society and beyond: critical issues for social theory, ed. B. Adam, U. Beck, and J.V. Loon. London: Sage Publications.

Beck, U. 2009. World at risk. Cambridge: Polity Press.

Beck, U. 2010a. Climate for change, or how to create a green modernity? Theory, Culture and Society 27(2-3): 254-266. doi:10.1177/0263276409358729.

Beck, U. 2010b. Sociedade de Risco: Rumo a uma outra modernidade. São Paulo: Editora 34.

Biermann, F. 2014. Governance in the Anthropocene: towards planetary stewardship. 4th Interactive Dialogue of the United Nations General Assembly on Harmony with Nature, New York City.

Biermann, F., et al. 2012. Navigating the Anthropocene: improving earth system governance. Science 335: 1306-1307.

Bulkeley, H. 2001. Governing climate change: the politics of risk society? Transactions of the Institute of British Geographers 26(4): 430-447.

Bulkeley, H., and P. Newell. 2010. Governing climate change. New York: Routledge.

Chan, C.K., and X. Yao. 2008. Air pollution in mega cities in China. Atmospheric Environment 42: 1-42.

Ferreira, L.C., and F. Barbi. 2013. Some issues about environmental concerns in Brazil and China (social justice and transitional societies). In China and Brazil: challenges and opportunities, ed. L.C. Ferreira, and J.A.A. Guilhon. São Paulo: Ed. Annablume.

Ferreira, L.C., and F. Barbi. 2014. Environmental concerns in Brazil and China (environmental issues in transitional societies). Culture della Sostenibilità 13: 95-106.

Ferreira, L.C. and S.B.F. Tavolaro. 2008. Environmental concerns in contemporary Brazil: an insight into some theoretical and societal backgrounds (1970s-1990s). International Journal of Politics, Culture, and Society. 19(3-4):161-177. http://www.jstor.org/stable/40206139?seq=1\#page_scan_ tab_contents.

Ferreira, L.C., F. Barbi, and M. Giesbrecht. 2016. Global environmental changes: environmental policies in China and Brazil. Tempo do Mundo 2(1): 99.

Giddens, A. 2005. Mundo em descontrole. O que a globalização está fazendo de nós. Rio de Janeiro: Record.

Giddens, A. 2009. The politics of climate change. Cambridge: Polity Press.

Huang, X., D. Zhao, C.G. Brown, Y. Wu, and S.A. Waldron. 2010. Environmental issues and policy priorities in china: a content analysis of government documents. China: An International Journal 8(2): 220-246.

Hung, M., and T.C. Tsai. 2012. Dilemma of choice: China's response to climate change. Revista Brasileira de Política Internacional 55: 104-124.

IPCC-Intergovernmental Panel on Climate Change. 2007. Climate change 2007: synthesis report. Cambridge: Cambridge University Press.

IPCC-Intergovernmental Panel on Climate Change. 2013. Summary for policymakers. In: Climate change 2013: the physical science basis, eds. Contribution of Working Group I to the Fifth Assessment Report of the Intergovernmental Panel on Climate Change, Stocker, T.F., D. Qin, G.-K. Plattner, M. Tignor, S.K. Allen, J. Boschung, A. Nauels, Y. Xia, V. Bex and P.M. Midgley. Cambridge, New York: Cambridge University Press. 
Keith, M., S. Lasch, J. Arnoldi, and T. Rooker. 2014. China: constructing capitalism: economic life and urban change. London and New York: Routledge.

Macbean, A. 2007. China's environment: problems and policies. The World Economy 30: 292-307.

Moreira, H.M. 2015. A nova Geopolítica das Mudanças Climáticas: o papel de Estados Unidos e China. Tese do Programa de Doutorado em Geografia: Universidade de São Paulo.

Nobre, C. et al. 2010. Vulnerabilidades das Megacidades Brasileiras às Mudanças Climáticas: Região Metropolitana de São Paulo. Centro de Ciência do Sistema Terrestre do Instituto Nacional de Pesquisas Espaciais (INPE), Núcleo de Estudos de População da Universidade de Campinas (UNICAMP). Faculdade de Medicina da Universidade de São Paulo (USP), Instituto de Pesquisas Tecnológicas de São Paulo (IPT), Universidade Estadual Paulista (UNESP-Rio Claro).

Oliveira, A. P. 2011. A China abraça a causa verde. In Estratégia, eds. A. Moreira and P. Ramalho. Volume XX. Lisboa: Instituto Português da Conjuntura Estratégica.

PBMC-Painel Brasileiro de Mudanças Climáticas. 2013. Base Científica das Mudanças Climáticas. $1^{\circ}$. Relatório de Avaliação Nacional. Volume 1. Rio de Janeiro: PBMC.

Pittock, A.B. 2005. Climate change: turning up the heat. London: Earthscan.

Rockström, J. 2009. Planetary boundaries: exploring the safe operating space for humanity. Nature 461: 472-475.

Viola, E. 2015. Entrevista para Observatório do Clima. Disponível em: http://www.observatoriodoclima. eco.br/proposta-do-brasil-em-paris-vai-ser-ruim/. acesso em 8 Oct 2015.

Viola, E., and M. Franchini. 2012. Climate politics in Brazil: public awareness, social transformations and emissions reduction. In Feeling the heat: the politics of climate policy in rapidly industrializing countries, ed. I. Bailey, and H. Compston. Hampshire: Palgrave.

Viola, E., M. Franchini, and T.L. Ribeiro. 2013. Sistema Internacional de Hegemonia Conservadora: Governança Global e Democracia na Era da Crise Climática, 1st edn, vol 1. São Paulo: Annablume.

Will, S., J. Grinevald, P. Crutzen, and J. Mcneill. 2011. The Anthropocene: conceptual and historical perspectives. Phil. Trans. R. Soc. A 369: 842-867.

Wilbanks, T., and R.W. Kates. 1999. Global change in local places: how scales matters. Climatic Change 43: 601-628.

Xie, L. 2011. China's environmental activism in the age of globalization. Asian Politics and Policy 3(2): $207-224$.

Young, O., et al. 2006. The globalization of socio-ecological systems: an agenda for scientific research. Global Environmental Change 16: 304-316.

Zehr, S. 2014. The sociology of global climate change. Wires Clim Change. doi:10.1002/wcc.328.

Leila da Costa Ferreira is a full professor in the Institute of Philosophy and Human Sciences and in the Center for Environmental Studies and Research (NEPAM) at Campinas State University (UNICAMP), Brazil. She is a faculty member of the Earth System Governance Project.

Fabiana Barbi is a post-doctoral researcher in the Center for Environmental Studies and Research (NEPAM) at Campinas State University (UNICAMP), Brazil. She is a visiting scholar in the Center for US-China Policy Studies (CUSCPS) at San Francisco State University. She is a research fellow of the Earth System Governance Project. 